\title{
ИССЛЕДОВАНИЕ БАЛХАШИТА
}

\section{1. Состав битумоида}

Одним из интригующих вопросов в органической, геохимии является генезис горючих ископаемых сапропелитового типа (горючие сланцы, богхеды, истинные сапропелиты). Образование гумолитов происходит и в настоящее время в широком масштабе, но торфяная стадия фоссилизации водорослевого материала известна на примере двух каустобиолитов - куронгита (Австралия) и балхашита (Средняя Азия).

Образование балхашита в заливе Ала-Куль озера Балхаш могли наблюдать еще в начале текущего столетия, но вследствие изменения водного режима озера его накопление прекратилось. В $1920-1935$ гг. балхашит подвергался интенсивному исследованию $\left[{ }^{1-5}\right]$. Исходными биологическими веществами для образования балхашита были водоросли Botriococcus Braunii, богатые жирами. Мертвый планктон на дне озера проходит анаэробную (сероводородную) стадию диагенеза, после чего выбрасывается волнами на берег, где его преобразование заканчивается уже в окислительных условиях. Именно при исследовании формирования балхашита Г. Л. Стадников $[2,3,4]$ пришел к выводу, что сапропелиты образуются главным образом из ненасыщенных жирных кислот в результате их полимеризации, ангидризации и декарбоксилирования, причем важную роль здесь играют окислительные реакции.

Балхашит встречается в виде отдельных скоплений, состоящих из небольших кусков, рыхлый, трещиноватый, от светлокоричневого до черного цвета. Г. Л. Стадников [ $\left.{ }^{4}\right]$ разделяет балхашит по возрасту на три типа: молодой (тонкие пленки), обыкновенный (бурый) и старый (черный).

Целью наших работ было всестороннее исследование балхашита на молекулярном уровне и обсуждение путей его генезиса. Изучению подвергались три пробы (представил геолог В. К. Крюков): 1) балхашит темнобурого цвета, отобранный неподалеку от современной береговой линии озера; 2) балхашит серочерного цвета - на повышенных участках берега; 3) рассеянное органическое вещество - из песка на берегу озера. Дальше эти пробы называются условно «бурый», «черный» и «расссянный» балхашит. Первые две пробы умеренно эластичны, и кроме цвета, по внешнему виду они мало отличаются. Так как балхашит в настоящее время не образуется, вместо молодого балхашита исследовали сапропелеподобное вещество, отобранное на берегу озера, которое является продуктом относительно недавнего диагенеза планктона, но не всегда составляет промежуточное звено обрагования балхашита. 


\section{Методика анализа}

Анализ балхашита проводили по комплексной схеме, сочетающей деструктивные и хроматографические методы [6]. Настоящая работа посвящена растворимой части балхашита - битумоиду. Из измельченного вещества хлороформом экстрагировали битумоид А и после обработки $10 \%$-ной соляной кислотой - смесью спирта и бензола $(1: 3)$ - битумоид С. Кислоты извлекали из битумоидов 0,5 н. спиртовым раствором КОН. Нейтральный битумоид разделяли на группы препаративной тонкослойной хроматографией, адсорбентом служил силикагель L (100-160 мкм), элюентом - $\mu$-гексан. При разделении кислот использовали соответственно силикагель «Силохром С-80» $(80-100 м \kappa м)$ и смесь эфира и $H$-гексана $(3: 7)$. Индивидуальный состав углеводородов и кислот (в виде метиловых эфиров) определяли на газовом хроматографе «Хром-4». Использовали колонки длиной $4-4,7, \mu$, диаметром 3 мм. Неподвижными фазами служили Е 301 и XE 60, 3-5\% от носителя - хроматона N AW DMCS.

Элементный состав балхашита. Балхашит отличается высоким содержанием органического вещества (см. табл. 1). Минеральная часть представлена главным образом кварцевым песком. Элементные составы обеих проб балхашитов близки. Содержание углерода немного больше, чем определил Г. Л. Стадников $\left[{ }^{4}\right]$ в обыкновенном балхашите, и соответствует его черной разновидности. Элементный состав балхашита не отличается от соответствующих данных многих сапропелитов (горючих сланцев, богхедов) и куронгита $\left[{ }^{7}\right]$, одновременно близок к составу полиненасыщенных жирных кислот, что отмечено уже многими исследователями. Атомное отношение водорода и углерода превышает 1,7; такое высокое отношение редко наблюдается в твердых каустобиолитах. Низкое содержание азота и серы указывает на небольшую роль бакте-

Таблица 1

Характеристика исходного и дебитуминизированного балхашита, вес. \%

\begin{tabular}{|c|c|c|c|c|c|c|}
\hline \multirow[b]{2}{*}{ Показатели } & \multicolumn{3}{|c|}{ _... Исходный ____ } & \multicolumn{3}{|c|}{ Дебитуминизированный } \\
\hline & бурый & черный & $\begin{array}{l}\text { pacce- } \\
\text { янный }\end{array}$ & бурый & черный & \begin{tabular}{|} 
pacce- \\
янный
\end{tabular} \\
\hline $\begin{array}{l}\text { Влага аналитическая, } W^{a} \\
\text { Зола прокаливания, } A^{c} \\
\text { Минеральная углекислота, } \mathrm{CO}_{2}\end{array}$ & $\begin{array}{l}1,2 \\
9,0 \\
0\end{array}$ & $\begin{array}{l}1,0 \\
6,0 \\
0\end{array}$ & $\begin{array}{r}0,9 \\
90,5 \\
4,4\end{array}$ & $\begin{array}{l}0,8 \\
4,1 \\
0\end{array}$ & $\begin{array}{l}0,6 \\
3,0 \\
0\end{array}$ & \\
\hline $\begin{array}{l}\text { Условная органическая масса, } \\
100-\left(\mathrm{CO}_{2}^{c}+A^{c}\right)\end{array}$ & 91,0 & 94,0 & 5,1 & 95,9 & 97,0 & \\
\hline $\begin{array}{l}\text { Сера, общая } \\
\text { пиритная } \\
\text { органическая (по разности) }\end{array}$ & $\begin{array}{l}0,95 \\
0,03\end{array}$ & $\begin{array}{l}0,66 \\
0,01\end{array}$ & 0,22 & $\begin{array}{l}1,05 \\
0,04\end{array}$ & $\begin{array}{l}0,58 \\
0,02\end{array}$ & \\
\hline $\begin{array}{l}\text { Элементный состав органического ве- } \\
\text { щества: } \\
\mathrm{C} \\
\mathrm{H} \\
\mathrm{N} \\
\mathrm{S}_{\text {opr. }} \\
\mathrm{O} \text { (по разности) } \\
\mathrm{H} / \mathrm{C} \text { атом. }\end{array}$ & $\begin{array}{c}0,92 \\
77,1 \\
11,1 \\
0,7 \\
0,9 \\
10,2 \\
1,73\end{array}$ & $\begin{array}{c}0,65 \\
75,5 \\
10,7 \\
0,7 \\
0,6 \\
12,5 \\
1,70\end{array}$ & & $\begin{array}{c}1,01 \\
74,5 \\
10,7 \\
0,8 \\
1,0 \\
13,0 \\
1,72\end{array}$ & $\begin{array}{c}0,56 \\
74,4 \\
11,0 \\
0,7 \\
0,6 \\
13,3 \\
1,77\end{array}$ & $\begin{array}{r}71,2 \\
10,0 \\
0,9 \\
1,4 \\
16,5 \\
1,70\end{array}$ \\
\hline
\end{tabular}

* Обогащенные пробы содержат $84,2 \%$ уОМ. 
риальных метаболитических процессов. Сульфатная сера отсутствует, пиритная присутствует в следовых количествах. Хотя рассеянный балхашит содержит немного больше кислорода, он - типичный зрелый сапропелитовый материал, сильно отличающийся от сапропеля.

Характеристика битумоидов. Выход и состав битумоидов представлен в табл. 2. Оба истинные балхашиты - бурый и черный, содержат одинаковое количество суммарного битумоида - $13-14 \%$, что значительно ниже, чем было установлено в прежних исследованиях [4], где растворителями извлекали 25-40\% экстракта. Предполагая более высокий возраст наших проб (при этом, бурый моложе черного), можем сделать вывод, что с созреванием содержание низкомолекулярных веществ в балхашите уменьшается и понижается их кислотность, кислоты превращаются в кероген. Значительна доля битумоида С. Так как минерального вещества мало, он связан с органическим веществом и освобождается при кислотном гидролизе.

Основную долю битумоидов составляют кислоты, что согласуется с прежними исследованиями [ $\left.{ }^{4}\right]$. Характерно высокое содержание жирных кислот (одно- и двухосновных), которые были отделены от полифункциональных (высокомолекулярных) кислот при помощи тонкослойной хроматографии.

Выход и состав битумоида, выделенного из рассеянного в песке органического вещества, значительно отличается от соответствующих показателей балхашита.

Состав углеводородов. Содержание углеводородов в битумоидах низкое, это характерно для каустобиолитов невысокой степени превращенности. Состав н-углеводородов представлен на рис. 1, н-парафины бурого и черного балхашита имеют близкий состав. Концентрационный максимум находится у парафинов $\mathrm{C}_{23}-\mathrm{C}_{27}$, преобладание парафинов с нечетным числом атомов углерода - невысокое. Подобные парафины встречаются во многих горючих сланцах и каменных углях. Обычно считается, что они имеют бактериальное происхождение.

Присутствует также заметное количество $н$-олефинов, представлен-

Таблица 2

\section{Выход и состав битумоидов}

\begin{tabular}{l|c|c}
\hline Показатели & \multicolumn{2}{|c}{ Исходный балхашит } \\
\cline { 2 - 3 } & бурый & черный $\mid$ рассеянный \\
\hline
\end{tabular}

Выход от органического вещества, \%

битумоид $\mathrm{A}$
битумоид $\mathrm{C}$
всего $(\mathrm{A}+\mathrm{C})$

Кислотное число ма $\mathrm{KOH} / 2$ битумоид А битумоид C

Групповой состав, \%:

неароматические углеводороды

одноядерные ароматические углеводороды полициклические ароматические углеводороды малополярные гетероатомные соединения сильнополярные гетероатомные соединения жирные кислоты поликарбоновые кислоты

$\begin{array}{rrr}5,0 & 8,1 & 1,6 \\ 8,7 & 5,4 & 2,0 \\ 13,7 & 13,5 & 3,6 \\ 152 & 85 & \\ 117 & 53 & \end{array}$

$\begin{array}{rrr}1,1 & 2,0 & 7,5 \\ 0,2 & 0,3 & 1,7 \\ 0,1 & 0,2 & 0,6 \\ 0,2 & 1,4 & 1,2 \\ 10,0 & 11,2 & 14,0 \\ 43,0 & 50,5 & 11,9 \\ 16,0 & 20,6 & 6,8\end{array}$

$\begin{array}{llll}\text { Bcero } & 70,6 & 86,2 & 43,1\end{array}$




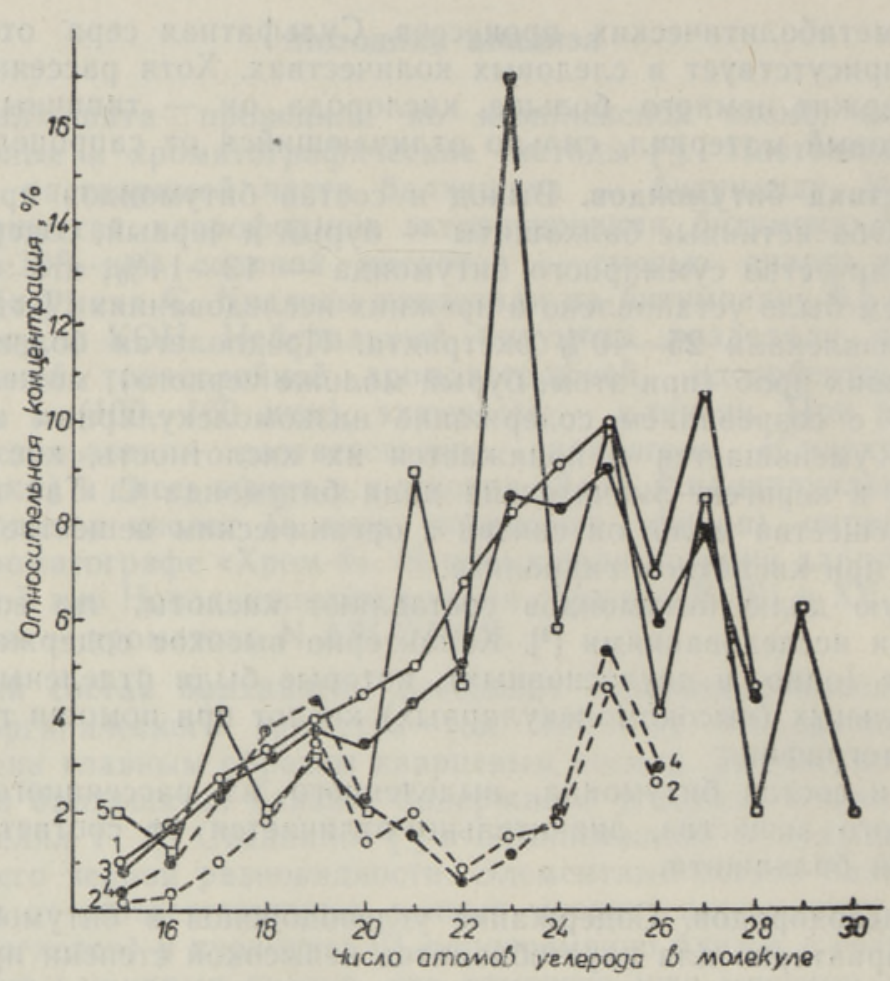

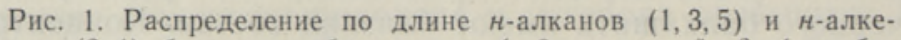
нов $(2,4)$ битумоида балхашита. 1,2 - черный; $3,4-6$ рый; 5 - рассеянный.

ных 1-изомерами. Олефины имеют два концентрационных максимума, при $\mathrm{C}_{19}$ и $\mathrm{C}_{25}$. Наличие олефинов в твердых каустобиолитах - редкое явление. Обычно генезис олефинов связывается с дегидратацией жирных спиртов, но в этом случае должны образоваться преимущественно четные олефины, в балхашите наблюдается преобладание нечетных олефинов. Таким образом, генезис олефинов и их связь с остальными группами остаются нерешенными.

Ациклических изопреновых углеводородов регулярного строения мало - сумма пристана $\left(i \mathrm{C}_{19}\right)$ и фитана $\left(i \mathrm{C}_{20}\right)$ составляет половину близкокипящих $\mu$-парафинов $\mathrm{C}_{17}$ и $\mathrm{C}_{18}$; оба изопреноида присутствуют в равном количестве.

В большом количестве присутствует нерегулярный изопреновый углеводород сквалан $\left(i \mathrm{C}_{30}\right)$, концентрация которого значительно превышает концентрацию близкокипящего $\boldsymbol{H}$-парафина $\mathrm{C}_{27}$. Сквалан встречается в седиментах редко и в небольшом количестве.

Состав углеводородов балхашита и куронгита $\left[{ }^{8}\right]$ очень близок. В куронгите также присутствуют 1-олефины с тождественным составом. Различие в том, что максимум балхашита - в интервале $\mathrm{C}_{21}-\mathrm{C}_{27}$.

Особое отличие углеводородов балхашита - наличие в большей концентрации двух углеводородов, температура кипения которых такая же, как у $\boldsymbol{H}$-парафинов $\mathrm{C}_{29}$ и $\mathrm{C}_{31}$. По газохроматографической и адсорбционной характеристике они могли быть из группы стеранов и тритерпанов [9], но не имеют оптической активности, и по '${ }^{1} \mathrm{H}$ ЯМР- и ИК- 


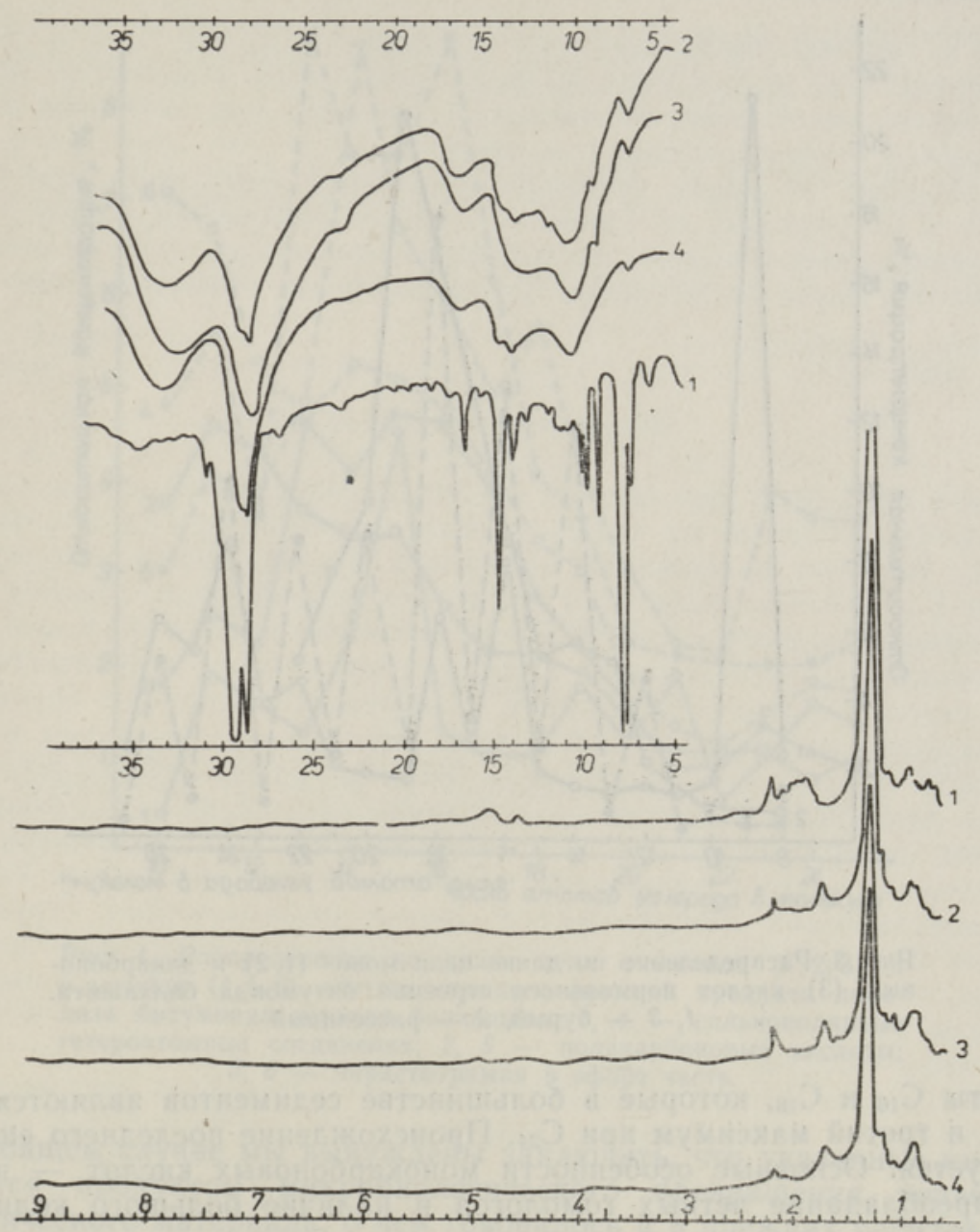

Рис. 2. ИК- и ${ }^{1} \mathrm{H}$ ЯМР-спектры фракций тонкослойного разделения битумоида балхашита. 1 - неароматические углеводороды из черного балхашита, сильнополярные гетероатомные соединения из: 2 - бурого, 3 - черного, 4 - рассеянного балхашита.

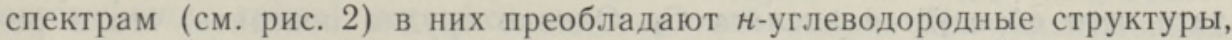
имеющие боковые цепи и содержащие ненасыщенные двойные связи.

Совсем другой состав имеют углеводороды, выделенные из рассеянного органического вещества песка. Распределение н-парафинов по длине углеродной цепи такое же, как в балхашите, но они имеют относительно высокую нечетность. Отсутствуют олефины, сквалан и циклические изопреноиды, но много пристана и фитана. Кажется, что углеводороды балхашита и рассеянного вещества ничего общего между собой не имеют.

Характеристика жирных кислот. Қислоты являются основными компонентами битумоида балхашита; состав кислот бурого и черного балхашита близок. Одно- и двухосновные кислоты присутствуют в приблизительно равных количествах.

Характерной особенностью монокарбоновых кислот балхашита является высокое содержание гомолога $\mathrm{C}_{9}$. Второй максимум составляют 


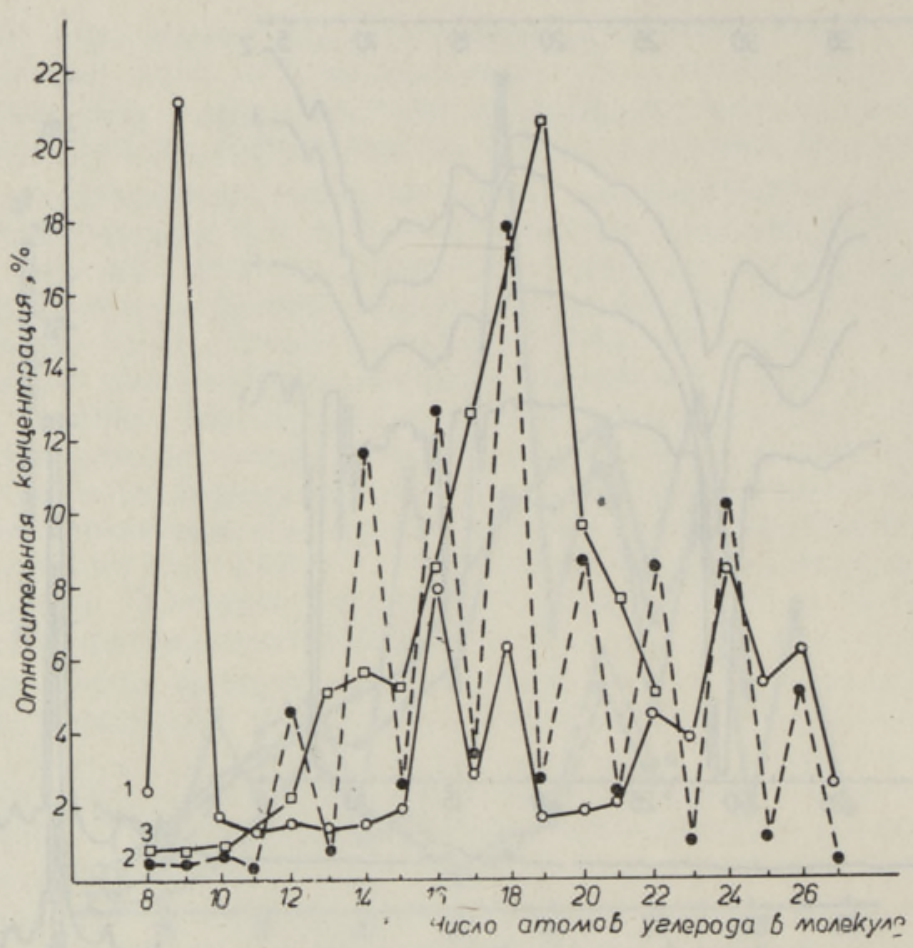

Рис. 3. Распределение по длине цепи моно- $(1,2)$ и дикарбоновых (3) кислот нормального строения битумоида балхашита. 1,3 - бурый, 2 - рассеянный.

кислоты $\mathrm{C}_{16}$ и $\mathrm{C}_{18}$, которые в большинстве седиментов являются главными, и третий максимум при $\mathrm{C}_{24}$. Происхождение последнего еще дискутируется. Основные особенности монокарбоновых кислот - небольшое преобладание четных гомологов и наличие большого количества кислоты $\mathrm{C}_{9}$.

В биологической продукции кислоты $\mathrm{C}_{6}-\mathrm{C}_{10}$ присутствуют в незначительном количестве. Указанные кислоты обнаружены в некоторых горючих сланцах $\left[{ }^{10,11}\right]$, где они могут быть продуктами диагенетического превращения. В настоящем случае логично предположить окислительную деструкцию олеиновой кислоты по двойной связи, в результате чего образуется кислота $\mathrm{C}_{9}$. Однако трудно поверить, что в результате абиогенеза образуется только одно соединение.

Кислоты рассеянного органического вещества имеют совсем другой состав: они распределены более равномерно, превалируют четные гомологи, отсутствует кислота $\mathrm{C}_{9}$. Присутствует небольшое количество изопреновых кислот $i \mathrm{C}_{16}, i \mathrm{C}_{18}$ и $i \mathrm{C}_{20}$.

Длинноцепочечные $\alpha \omega$-дикарбоновые кислоты установлены в некоторых древних и современных седиментах $\left[{ }^{12,13}\right]$, обычно присутствуют гомологи только с четным числом углеродных атомов. В пробах балхашита дикарбоновые и одноосновные кислоты присутствуют в равных количествах (см. рис. 3). Индивидуальный состав кислот обеих проб близок, присутствуют кислоты $\mathrm{C}_{12}-\mathrm{C}_{22}$ с четко выраженным максимумом при $\mathrm{C}_{19}$, концентрация гомологов изменяется монотонно. Дикарбоновые кислоты балхашита имеют ряд отличительных черт, кажется, что они не имеют ничего общего с другими $\boldsymbol{H}$-алкановыми структурами. 


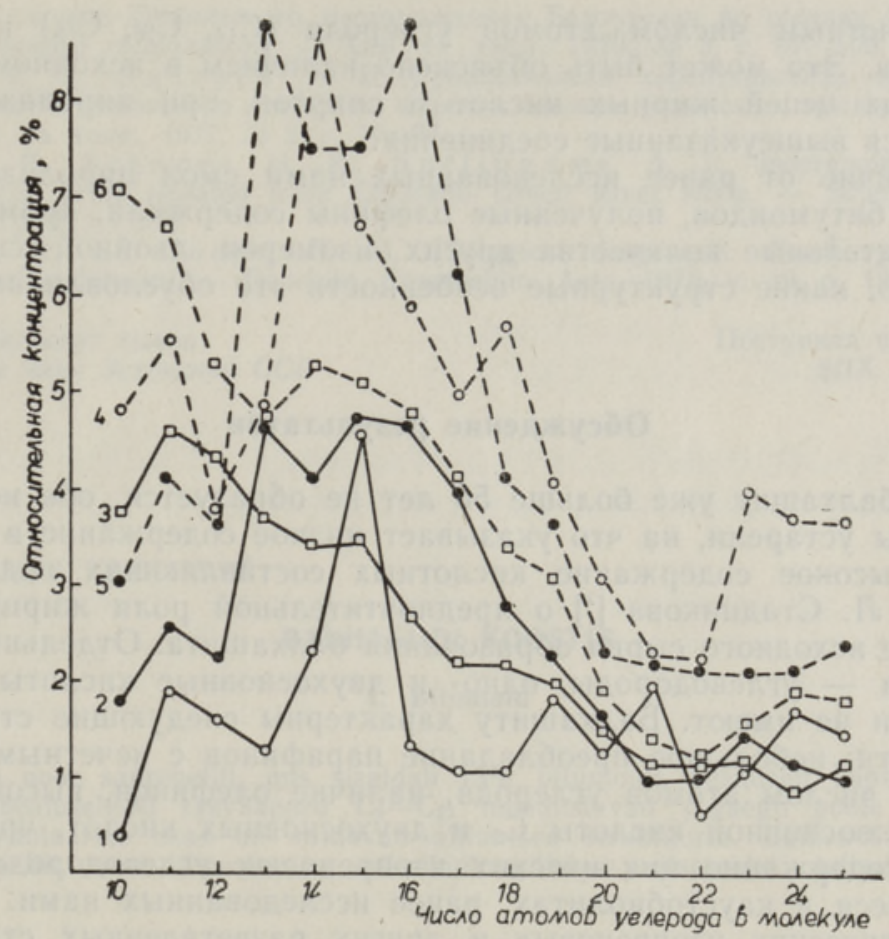

Рис. 4. Распределение по длине цепи н-алканов $(1,2,3)$ и н-алкенов $(4,5,6)$ соответствующих фракций продукта пиролиза битумоида черного балхашита. 1, 4- сильнополярные гетероатомные соединения; 2, 5 - поликарбоновые кислоты; 3,6 - нерастворимая в эфире часть.

В настоящем случае мы вынуждены заключить, что указанные кислоты являются продуктом микробиологического превращения первичного биологического материала, о чем говорилось и в прежних работах $\left[{ }^{12,13}\right]$.

В рассеянном органическом веществе песка дикарбоновые кислоты присутствовали только в следовых количествах.

Характеристика высокомолекулярной части битумоида. При разделении составляющих битумоида способом тонкослойной хроматографии их высокомолекулярные компоненты - асфальтены (20-30\% соответствующих групп) остаются на стартовой линии. Для исследования состава алифатических структур асфальтенов проводили их пиролиз в стеклянной трубке при $400-500^{\circ}$. Асфальтены были выделены из нейтрального битумоида и кислотной части; третью пробу составили нерастворимые кислотные соединения, которые осаждались при подкислении щелочного раствора омыления битумоида.

Главными компонентами пиролизатов являются $H$-углеводороды, состав которых представлен на рис. 4. Олефинов значительно больше, чем парафинов. Такое явление часто наблюдается при пиролизе битумоидов и других органических соединений, из которых образуется много жидких продуктов. Отношение - олефин/парафин уменьшается в ряду исходных асфальтенов: нейтральные $>$ кислотные $>$ нерастворимые. Этот порядок совпадает с предполагаемым выходом жидких продуктов при пиролизе.

В продуктах пиролиза наблюдается некоторое преобладание оле- 
финов с четным числом атомов углерода $\left(\mathrm{C}_{14}, \mathrm{C}_{16}, \mathrm{C}_{18}\right)$ и нечетных парафинов. Это может быть объяснено наличием в исходном веществе углеродных цепей жирных кислот и спиртов, при пиролизе которых образуются вышеуказанные соединения.

В отличие от ранее исследованных нами смол пиролиза твердых топлив и битумоидов, полученные олефины содержали, кроме 1-изомеров, значительные количества других изомеров двойной связи. Нам неизвестно, какие структурные особенности это обусловливают.

\section{Обсуждение результатов}

Так как балхашит уже больше 50 лет не образуется, обе исследованные пробы устарели, на что указывает низкое содержание в них битумоида. Высокое содержание кислотных составляющих подтверждает вывод Г. Л. Стадникова [ [4] о предпочтительной роли жирных кислот в качестве исходного сырья образования балхашита. Отдельные группы битумоида - углеводороды, одно- и двухосновные кислоты генетической связи не имеют. Балхашиту характерны следующие структурные особенности: небольшое преобладание парафинов с нечетным и кислот с четным числом атомов углерода, наличие олефинов, высокое содержание одноосновной кислоты $\mathrm{C}_{9}$ и двухосновных кислот, чрезвычайно высокое содержание циклических изопреновых углеводородов, не наблюдавшееся в каустобиолитах, ранее исследованных нами. Содержание ациклических изопреновых и других разветвленных структур низкое. Большинство этих показателей позволяет выдвинуть предположение, что исходное сырье формирования балхашита подвергалось сильной бактериальной переработке и балхашит образовался уже из вторичных продуктов.

Рассеянное органическое вещество имеет, наверное, тот же первичный источник, что и балхашит, но его состав, отличающийся от балхашита, более близок к составу водорослей. Предполагаем, что сырье рассеянного вещества не проходило восстановительную (микробиологическую) стадию - после отмирания было сразу выброшено на берег. Это и может объяснить его различие в составе.

\section{ЛИТЕРАТ У РА}

1. Zelinsky, N. D. Künstliche Naphtha aus Balchasch-Sapropeliten. - Brennstoff-Chemie, 1925, Bd. 6, N 23, S. 365-380.

2 Stadnikov, G., Wodschinskaja, Z. Ober die Umwandlung der Fettsäuren im Laufe der geologischen Zeitperioden. - Brennstoff-Chemie, 1930, Bd. $11, \mathrm{~N} 20$, S. $414-416$.

3. Stadnikow, G. L. Balchaschit. - Brennstoff-Chemie, 1933, Bd. 14, N 12, S. $227-229$.

4. С т а дни ков Г. Л. Происхождение углей и нефти. М.-Л., 1937, с. 10С-111.

5. Stadnikoff, G., Egorowa, O. Zur Frage über die Umwandlung der Fettsäuren im Laufe geologischer Zeitperioden. - Brennstofif-Chemie, 1936, Bd. $17, \mathrm{~N} 3$, S. $48-49$.

6. Klesment, I. Application of chromatographic methods in biogeochemical investigation. - J. Chrom., 1974, v. 91, p. 705-713.

7. Кей н Р. Ф. Природа и строение куронгита. - В кн.: Разработка и использование запасов горючих сланцев. Таллин, 1970, с. $195-201$.

8. Douglas, A. G., Eglinton, G., Maxwell, J. R. The hydrocarbons of coorongite. - Geochim. Cosmochim. Acta, 1969, v. 33, p. 569-577.

9. Dick, H. H. Organisches Material am nordwestafrikanischen Kontinentalrand. Erdöl u. Kohle, 1979, Bd. 32, H. 10, S. 467-473.

10. У ров К. Э., Л истрем А. И. К характеристике органического вещества горю- 
чих сланцев Припятского месторождения Белоруссии по составу битумоида и щелочного гидролизата. - Хим. тв. топл., 1979, № 3, с. 97-103.

11. У ров К. Э., Ли ст рем А. И. Сравнительная характеристика органического вещества девонского и юрского горючих сланцев ухтинского месторождения. Хим. тв. топл., 1977, № 2, с. $71-77$.

12. Haug, P., Schnoes, H. K., Burlingame, A. L. Isoprenoid and dicarboxylic acids isolated from Colorado Green River shale. - Science, 1967, v. 158 , p. $772-773$.

13. Johns, R. B., Onder, O. M. Biological diagenesis: dicarboxylic acids in recent sediments. - Geochim. Cosmochim. Acta, 1975, v. 39, p. 126-136.

\author{
Ннститут химии \\ Академии наук Эстонской ССР
}

Поступила в редакцию

$8 /$ IX 1980

Linda POBUL, I. KLESMENT

\title{
BALHAŠIIDI KOOSTIS
}

\section{Bitumoid}

Balhašiit on noor sapropeliit, mis sisaldab $13 \%$ bitumoidi, peamiselt hapnikuühendeid. Uhe- ja kahealuselised rasvhapped $C_{9}-C_{27}$ moodustavad peaaegu poole bitumoidist, ka kõrgmolekulaarses osas on valdavad alifaatsed struktuurid. Balhašiit ei ole tüüpiline sapropeliit, tema lähteaine on mikrobioloogilistes protsessides oluliselt muutunud.

Linda POBUL, I. KLESMENT

\section{STUDY OF BALKHASHITE}

\section{The composition of bitumen}

Balkhashite is a young sapropelite containing $13 \%$ of bitumen, mainly oxygen compounds. Mono- and two-basic fatty acids $\mathrm{C}_{9}-\mathrm{C}_{27}$ make up almost a half of bitumens; aliphatic structures predominate also in the high-molecular part. Balkhashite is a nontypical sapropelite, its source material having considerably changed as a result of microbiological processes. 